\title{
Late-onset olfactory deficits and mitral cell loss in mice lacking prion protein with ectopic expression of Doppel
}

\author{
CHI-KYEONG KIM ${ }^{1}$, AKIKAZU SAKUDO ${ }^{1}$, YOJIRO TANIUCHI ${ }^{1}$, KAZUTO SHIGEMATSU ${ }^{2}$, \\ CHUNG-BOO KANG $^{3}$, KEIICHI SAEKI ${ }^{1}$, YOSHITSUGU MATSUMOTO ${ }^{1}$, SUEHIRO SAKAGUCHI ${ }^{4}$, \\ SHIGEYOSHI ITOHARA ${ }^{5}$ and TAKASHI ONODERA ${ }^{1}$
}

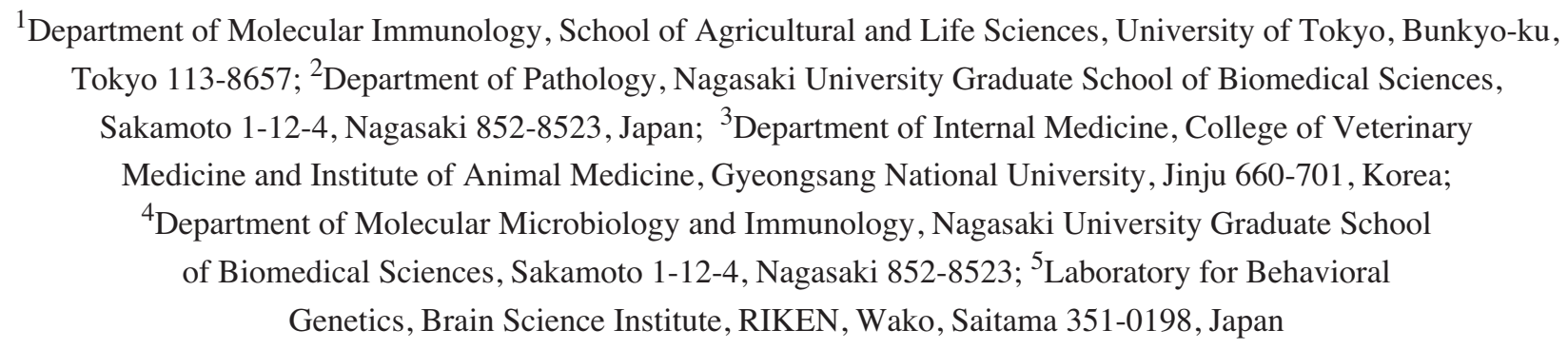

Received November 21, 2006; Accepted December 29, 2006

\begin{abstract}
Several lines of prion protein gene (Prnp)-knockout mice such as ZrchI, ZrchII, Npu, Ngsk and Rcm0 have been generated. Of these, ZrchII, Ngsk and Rcm0 exhibit late-onset ataxia due to ectopic expression of Doppel (Dpl); a result of damage to the splicing acceptor of Prnp exon 3. Recently, we developed another line of $\mathrm{Prnp}^{-/-}$mice (Rikn), which was generated by gene targeting with more nucleotides by replacing intron 2 with the pgk-neo gene (cf. Ngsk Prnp ${ }^{-/-}$ mice) and showed not only ataxia but also a lower olfactory sensitivity than the other Prnp $^{-/}$mouse line ZrchI at over 60 weeks of age. The histopathology of the elderly Rikn Prnp ${ }^{-1}$ mice showed mitral cell loss concomitantly observed with gliosis of astrocytes. Western blot analysis showed that Dpl was detected in the cerebrum, cerebellum and olfactory bulb of Rikn $\mathrm{Prnp}^{-/}$mice, where aberrant histopathology was observed. Thus, mitral cell loss and gliosis induced by ectopic Dpl expression were probably associated with the late-onset olfactory deficits in Rikn Prnp $^{-/-}$mice.
\end{abstract}

\section{Introduction}

Cellular prion protein $\left(\mathrm{PrP}^{\mathrm{C}}\right)$ is a glycosylphosphatidylinositol (GPI)-anchored protein highly expressed in the central nervous system (CNS). $\mathrm{PrP}^{\mathrm{C}}$ is expressed specifically in neurons and to a lesser extent in lympho-reticular tissues

Correspondence to: Dr Takashi Onodera, Department of Molecular Immunology, School of Agricultural and Life Sciences, University of Tokyo, Bunkyo-ku, Tokyo 113-8657, Japan

E-mail: aonoder@mail.ecc.u-tokyo.ac.jp

Key words: apoptosis, Doppel, olfactory bulb, prion protein, knock-out mouse
$(1,2)$. In attempts to study the function of $\operatorname{PrP}^{\mathrm{C}}$, several lines of prion protein gene (Prnp)-knockout mice have been generated using different designs of gene disruption. The first two lines of $\mathrm{Prnp}^{-/}$mice, ZrchI and Npu, showed normal development and growth $(3,4)$. However, the third line of $\mathrm{Prnp}^{-/-}$mice (Ngsk Prnp ${ }^{-/}$) developed late-onset ataxia accompanied by Purkinje cell degeneration (5). Recently, an additional independently generated Prnp $^{-/}(\mathrm{Rcm} 0)$ also manifested similar late-onset ataxia (6). It has been suggested that $\operatorname{PrP}^{\mathrm{C}}$ may have a role in the long-term survival of Purkinje neurons. However, it was unclear why Nsgk Prnp ${ }^{-/}$and Rcm0 Prnp $^{-/-}$mice developed fatal ataxia while the two other lines of $\mathrm{Prnp}^{-/}$mice (Zrch I and Npu) exhibited no such CNS dysfunctions. Previous studies on regions flanking the human, sheep and mouse Prnp in cosmid clones have failed to reveal any additional open-reading frames (ORF). In fact, a novel Doppel $(\mathrm{Dpl}) /$ prion protein $(\mathrm{PrP})$-like gene was located when subsequent sequencing of a cosmid clone isolated from an I/LnJ-4 mouse was attempted in downstream investigations of Prnp (6,7).

Discovery of the Dpl not only represents the first finding of PrP-related protein expression, but it also provides an explanation for some otherwise unaccountable characteristics in other lines of $\mathrm{Prnp}^{-/-}$mice described above. Dpl, a glycoprotein encoded by Prnd, harbours $\sim 25 \%$ sequence identity with two-thirds of the $\mathrm{C}$-terminal of $\operatorname{PrP}^{\mathrm{C}}$. This glycoprotein is predicted to contain three $\alpha$-helices and two disulfide bonds, albeit notably lacking an octarepeat domain located at the N-terminus of $\operatorname{PrP}^{\mathrm{C}}(6)$. Abundant Prnd mRNAs are not found in the brains of wild-type (WT) mice, although high levels of mRNA species of 1.7 and $2.7 \mathrm{~kb}$ are present in both the heart and testis (6). The Rcm0 and Ngsk lines differ from asymptomatic Prnp ${ }^{-/}$mice in that they carry genomic deletions that extend beyond the Prnp ORF, stretching to intron 2 at the 5' end and 3'-untranslated region at the 3 ' end of the Prnp mRNA. These deletions eliminate the Prnp exon 3 splice 
acceptor site and generate high levels of the Prnd transcript in the brain by an unusual mechanism(s) involving exonskipping and intergenic splicing (6).

A recently generated Prnp $^{-/-}$line, designated as Rikn by Yokoyama et al $(8,9)$, has exhibited no obvious behavioral changes with normal physical activity at a young age. However, similar to Ngsk and Rcm0 Prnp ${ }^{-/}$, Rikn Prnp $^{-/-}$mice manifested tremor and ataxia with aging. In contrast to studies of ZrchII, Ngsk and Rcm0 Prnp ${ }^{-/}$mice, Rikn Prnp ${ }^{-/-}$ mice showed a variety of CNS dysfunctions, including abnormal responses to olfactory stimulation. Histopathological studies revealed wide-spread neuronal degeneration in the Purkinje cells and olfactory bulb. In ZrchII, Ngsk and Rcm0 Prnp ${ }^{-/}$mice, degenerated neurons were not observed in the olfactory bulb and cerebrum. The above findings suggest that the third line of $\mathrm{Prnp}^{-/}$mice demonstrated olfactory abnormalities. The roles of the expression pattern of chimeric Prnp/Prnd in the cerebrum, cerebellum and olfactory bulb were correlated with Dpl expression and neuronal degeneration.

\section{Materials and methods}

Animals. Rikn Prnp ${ }^{-/}$(8,9), Ngsk Prnp ${ }^{-/}$(5) and ZrchI Prnp ${ }^{-/}$ (3) mice were housed in plastic cages (Clea, Tokyo, Japan). Mice, in groups of five per cage, were given food pellets (CE-2 $30 \mathrm{kGy}, \mathrm{Clea})$ and drinking water ad libitum. All experiments in the present study were approved by and performed under the guidelines of the University of Tokyo and the Ministry of Education, Culture, Sports Science and Technology of Japan. For the purpose of age-related analysis, mice were divided into two age categories, viz. the young $(<60$, or between 20 and 40 weeks) and the elderly (>60, or between 70 and 80 weeks).

Histopathological analysis. Mice were anaesthetized with diethylether and perfused transcordially with $4 \%$ paraformaldehyde fixative in phosphate-buffered saline (PBS) adjusted to $\mathrm{pH}$ 7.4. After perfusion, the brain of each animal was immediately removed and immersed in the fixative overnight at $4^{\circ} \mathrm{C}$. Coronal sections of the olfactory bulb and sagittal sections of the cerebrum and cerebellum were prepared. Tissue specimens were dehydrated with a graded ethanol series and embedded in paraffin. Serial sections $(6-\mu \mathrm{m}$ thickness) were deparaffinized in xylene and rehydrated in a series of graded ethanol before staining with hematoxylin and eosin (H\&E) reagent and subsequent observation under light microscopy. Purkinje cells of the cerebellum and mitral cells of the olfactory bulb were accordingly counted (magnification, $\mathrm{x} 200$ ) using 10 adjoining squares as a counting grid with each side measuring $100 \mu \mathrm{m}$. The adjoining squares were counted for each site, and the respective counts were indicated. Statistical significance was analyzed separately for each genotype by the unpaired Student's t-test.

Immunohistochemistry. Deparaffinized sections were digested with $20 \mu \mathrm{g} / \mathrm{ml}$ proteinase $\mathrm{K}$ for $15 \mathrm{~min}$ at room temperature before placement in methanol containing $3 \% \mathrm{H}_{2} \mathrm{O}_{2}$ for $30 \mathrm{~min}$ to neutralize endogenous peroxidase activity. After treatment with Block Ace (Dainippon Pharmaceutical, Tokyo, Japan) for $1 \mathrm{~h}$ at room temperature, the tissue sections were incubated overnight at $4{ }^{\circ} \mathrm{C}$ with one of the following primary antibodies: polyclonal rabbit anti-bovine GFAP (1:50 dilution, Dako, Tokyo, Japan) to characterize astrocytes; and polyclonal rabbit anti-ssDNA (1:500 dilution, Dako) to detect apoptotic cells. Following incubation with the primary antibody, sections were washed extensively in PBS/0.1\% Tween containing 10\% Block Ace for $30 \mathrm{~min}$. The sections were subsequently incubated with HRP-conjugated anti-rabbit immunoglobulin goat Fab' (Histofine Max $\mathrm{Po}^{\circledR}$, Nichirei, Tokyo, Japan) for $1 \mathrm{~h}$ at room temperature. Following 3 washings for $30 \mathrm{~min}$, the immunoreaction was visualized using 3,3'-diaminobenzidine-tetrachloride (DAB) (Histofine, Nichirei) for $5 \mathrm{~min}$ at room temperature. The sections were counterstained with Mayer's hematoxylin and examined by light microscopy (Olympus BX-51).

For immunofluorescence, polyclonal rabbit anti-cleaved caspase-3 and anti-caspase-10 (1:300 dilution, Cell Signaling, Beverly, MA, USA) were incubated overnight at $4^{\circ} \mathrm{C}$. After washing with PBS $/ 0.1 \%$ Tween-20 containing $10 \%$ Block Ace for $30 \mathrm{~min}$, tissue sections were subsequently incubated with the Alexa Flour R-546 anti-mouse IgG $(\mathrm{H}+\mathrm{L})$ goat antibody (1:200 dilution, Molecular Probes, Eugene, OR, USA) or the Alexa Flour R-488-labeled anti-rabbit IgG goat antibody (1:300 dilution, Molecular Probes) for $1 \mathrm{~h}$ at room temperature.

RT-PCR for Prnd mRNAs. Total RNA was isolated from the brains and testes of WT, ZrchI Prnp ${ }^{-/-}$and Rikn Prnp ${ }^{-/}$mice by TRIzol ${ }^{\circledR}$ reagent (Gibco BRL, Gaithersburg, MD, USA) according to the manufacturer's instruction. RNA (1 $\mu \mathrm{g})$ was denatured at $65^{\circ} \mathrm{C}$ for 5 min before being subjected to reverse transcription in a $40-\mu 1$ mixture containing $10 \mathrm{mM}$ Tris- $\mathrm{HCl}$ (pH 8.3), $50 \mathrm{mM} \mathrm{KCl,} 5 \mathrm{mM} \mathrm{MgCl} 2,1 \mathrm{mM}$ dNTPs (Takara, Ohtu, Japan) and 50 units of Moloney murine leukemia virus reverse transcriptase (M-MLV RT) (US Biochemicals, Swampscott, MA, USA) and $125 \mu \mathrm{M}$ oligo d(T) $)_{16}$ primer. RNA was reverse transcribed at $37^{\circ} \mathrm{C}$ for $45 \mathrm{~min}$, followed by enzymatic denaturation at $99^{\circ} \mathrm{C}$ for $8 \mathrm{~min}$. In performing the PCR, diluted cDNA was amplified in a reaction mixture containing $15 \mathrm{mM}$ Tris- $\mathrm{HCl}(\mathrm{pH} 8.0), 50 \mathrm{mM} \mathrm{KCl}, 15 \mathrm{mM}$ $\mathrm{MgCl}_{2}, 50$ pmol of each primer and 1.25 units of AmpliTaq gold polymerase (Perkin Elmer, Norwalk, CT, USA), and the following primers were used: PrPellf (5'-GGCAGGATC CTGGGCGCTGCGTCGCATCGGTGGCAG-3') and DPLSTOP-SR (5'-CTCGTCGACCTCTGTGGCTGCCAGCTT CATTGA-3') for Prnp/Prnd chimeric mRNA; DW189 (5'GCTCCAAGCTTCAGAGGCCACAGTAGCA-3') and DW112 (5'-CGGTTGGTCCACGGCGACCCGAA-3') for Prnd mRNA (6).

Odor recognition and discrimination test. Sixty-week-old mice were each placed in a transparent plastic cage $\left(19 \times 24.5 \times 13 \mathrm{~cm}^{3}\right)$ with 2 -cm-thick paper bedding, and the cage was covered by a wire-meshed lid. One $\mathrm{ml}$ of $2.5 \%$ lemon extract (Sunkist Growers, Tokyo, Japan) used to stain one side of a filter paper $(5 \times 5 \mathrm{~cm})$ provided positive olfactory cues while the other side moistened with sterilized distilled water was used as a control. During the experiment, this filter paper was cellophane-taped on the wall inside the cage at a height of $\sim 9 \mathrm{~cm}$ above the floor. To assess the mobility of 




Figure 1. Histopathological abnormality in the brain of 80 -week-old Rikn Prnp $^{-/}$mice. Sagittal sections (6- $\mu$ m thickness) of the brain were sectioned after fixation with $4 \%$ paraformaldehyde, and histological studies of the brain stem (A; scale bar, $100 \mu \mathrm{m}$ ), alveus (B; scale bar, $100 \mu \mathrm{m}$ ) and lemniscus trigeminalis (C; scale bar, $50 \mu \mathrm{m}$ ) of an 80-week old Rikn Prnp ${ }^{-/}$ mouse were conducted. The Rikn Prnp ${ }^{-/}$mouse showed vacuolar degenerations (arrows) and single cell necrosis (arrow heads).

mice, the cage was divided into 2 equal halves with a demarcation line, and the time required for the animal to move more than half of its body length (excluding tail) from one half to the other half of the cage was recorded with a digital stopwatch. Mobility levels were expressed as bisect/ sec. The cut-off time was designated as $300 \mathrm{sec}$. The cage was deodorized with isopropanol and dried after each test to prevent odor-induced repetitive exploratory behaviors (10).

Dpl detection with Western blotting. Dpl was detected as previously described (11). To fractionate tissue samples, $10 \%$ $(\mathrm{w} / \mathrm{v})$ homogenate was prepared in sterile PBS followed by sonication. After initial centrifugation at $600 \mathrm{x} \mathrm{g}$ for $15 \mathrm{~min}$ at $4^{\circ} \mathrm{C}$, the supernatant was further ultracentrifuged at $100,000 \mathrm{x} \mathrm{g}$ for $2 \mathrm{~h}$ at $4^{\circ} \mathrm{C}$. The pellet was suspended in ice-cold radioimmunoprecipitation assay (RIPA) buffer containing $10 \mathrm{mM}$ Tris- $\mathrm{HCl}$ (pH 7.4), 1\% deoxycholate, $1 \%$ Nonidet P-40, $0.1 \%$ sodium dodecyl sulfate (SDS), $150 \mathrm{mM} \mathrm{NaCl}, 2 \mu \mathrm{g} / \mathrm{ml}$ aprotinin, and $2 \mathrm{mM}$ phenylsulfonyl fluoride (PMSF). The protein concentration was determined by the Bradford assay according to the manufacturer's instructions (DC protein assay kit; Bio-Rad Laboratories Inc., Tokyo). Lysates were boiled in a 2 -fold volume of sodium dodecyl sulfatepolyacrylamide gel electrophoresis (SDS-PAGE) sample buffer [1 M Tris- $\mathrm{HCl}$ (pH 6.8), $200 \mathrm{mM}$ dithiothreitol, 10\% SDS, $2 \%$ bromophenol blue and $20 \%$ glycerol] for $5 \mathrm{~min}$. The samples were then subjected to electrophoresis in $12 \%$ SDS-polyacrylamide gels and transferred to polyvinylidene difluoride (PVDF) membranes (Hybond-P, Amersham, Piscataway, NJ, USA) for $60 \mathrm{~min}$ at 15 volts. The membrane was blocked with Block Ace (Dainippon Pharmaceutical, Japan) overnight at room temperature. Primary anti-Dpl rabbit antiserum (a kind gift from Dr Chen) was diluted 1:2500 in PBS/0.1\% Tween-20 containing 10\% Block Ace and incubated for $1 \mathrm{~h}$ at room temperature. After washing thrice with PBS $/ 0.1 \%$ Tween-20, the membrane was further incubated with horseradish peroxidase-conjugated anti-rabbit immunoglobulin antibodies (1:5000 dilution with PBS/0.1\% Tween-20 containing 10\% Block Ace) for $1 \mathrm{~h}$ at room temperature. Mouse hybridoma (T2) monoclonal antibody was used for PrP detection (12). T2 was kindly provided by Dr Tagawa (National Institute of Animal Health, Japan). Hybridoma was purified with the MabTrap ${ }^{\mathrm{TM}}$ kit (Amersham) according to the manufacturer's instructions. After treatments with primary antibodies, the blot was incubated with horseradish peroxidase-conjugated anti-mouse Ig sheep F $\left(a^{\prime}\right)_{2}$ fragment (1:5000 dilution), and subsequently washed thrice for $10 \mathrm{~min}$ in $\mathrm{PBS} / 0.1 \%$ Tween-20. Blots were developed by exposing the ECL-enhanced chemiluminescence reagent (Amersham) to Hyperfilm ${ }^{\mathrm{TM}}$ MP (Amersham) before being automatically processed in an X-ray film processor (Konica, Tokyo).

\section{Results}

After Rikn Prnp ${ }^{-/}$mice were sacrificed by anesthetic overdosage, histopathological studies were conducted (Fig. 1). Rikn $\mathrm{Prnp}^{-/}$mice stayed normal and healthy at $\leq 50$ weeks of age. At $>50$ weeks of age, some Rikn Prnp $^{-/}$mice showed an onset of symptoms such as trembling gait, intentional tremors and kyphosis. However, such signs were not observed in WT and ZrchI Prnp ${ }^{-/-}$mice. At 80 weeks of age, most of the Rikn Prnp ${ }^{-/}$mice showed vacuolar degenerations in the lemniscus trigeminalis and alveus (Fig. 1B and C). Intensive spongiform lesions and vacuolation of nerve cells were noted in the lemniscus trigeminalis (Fig. 1C), while degenerated and vacuolated nerve cells were located in the brain stem (Fig. 1A). Age-matched heterozygous or homozygous Prnp littermate mice showed no neurodegeneration in the brain regions (data not shown).

Although a $30.5 \%$ loss of mitral cells (Fig. 2D and E) along with a thickening of the external plexiform layer were noted, Rikn Prnp ${ }^{-/}$mice $\leq 50$ weeks of age indicated no significant mitral cell loss. Mild histological changes in the olfactory bulb were observed from 60 weeks of age in Rikn Prnp $^{-/}$mice. While no pathological changes and loss of mitral cells were observed in the young ( $<60$ weeks old) or elderly (>60 weeks old) ZrchI Prnp ${ }^{-/}$, Ngsk Prnp ${ }^{-/}$, Rikn Prnp ${ }^{+/}$and WT mice (Fig. 2A, C, and E), similar tendencies were noted in the accessory olfactory bulbs of all four mouse lines (WT, ZrchI, Ngsk, Rikn) (data not shown). 


\section{ZrchI}
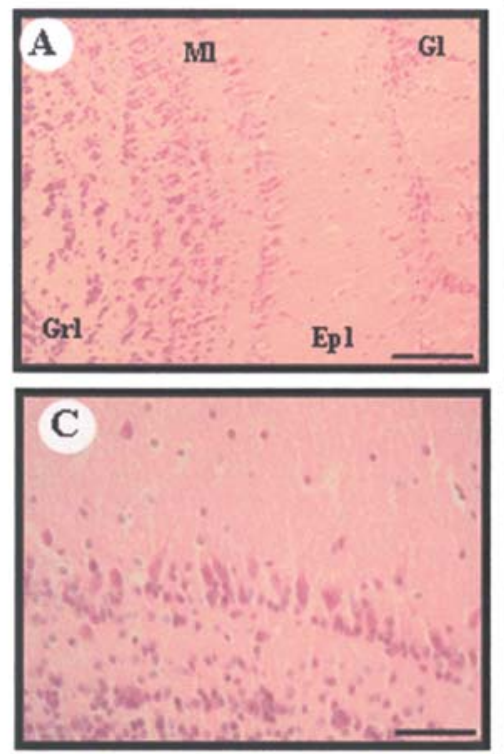

Rikn
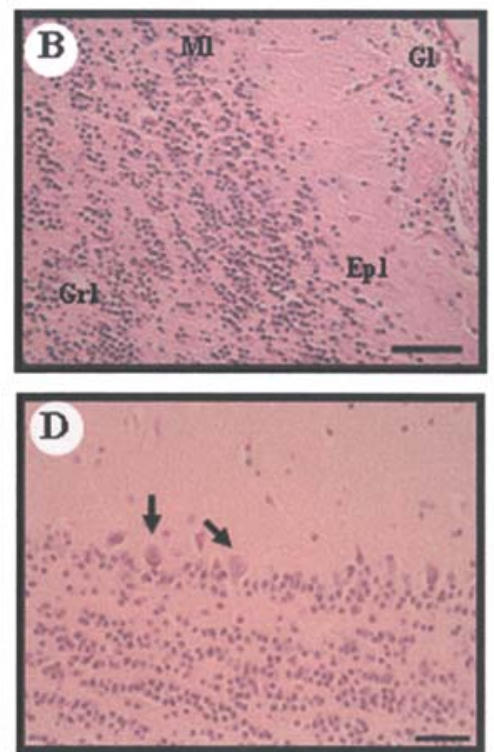

\section{Main} olfactory

bulb

80 weeks

E

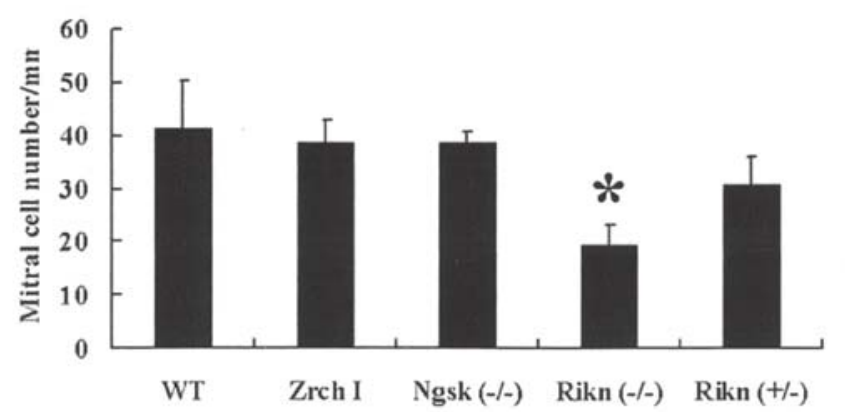

$\mathbf{F}$

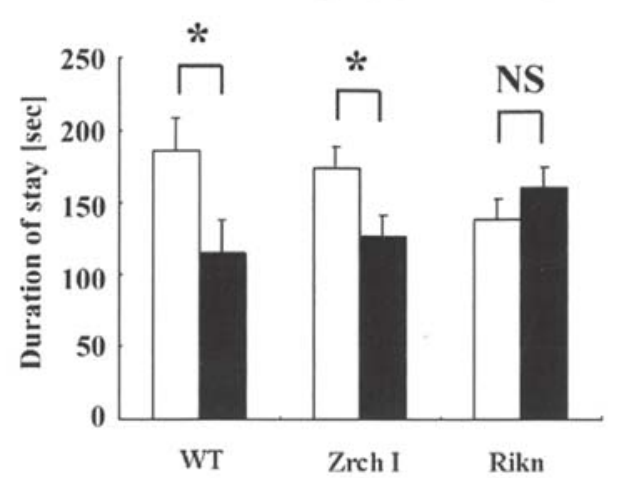

Figure 2. Olfactory functions and histopathological findings of the olfactory bulbs in 80-week-old wild-type (WT), ZrchI Prnp ${ }^{-/}$, Rikn Prnp ${ }^{-/}$and Prnp ${ }^{-/}$ mice. Histological studies of the main olfactory bulb of 80-week-old ZrchI Prnp ${ }^{-1}$ (A, C) and Rikn Prnp $/-$ (B, D) mice were performed. Coronal sections (6- $\mu \mathrm{m}$ thickness) were stained with the hematoxylin and eosin reagent. Rikn Prnp ${ }^{-/}$mice portrayed mitral cell loss (B, D) with a decreased thickness of the external plexiform layer in the main olfactory bulb (B). High magnification of a mitral cell (square) is indicated (D). Gl, glomerular layer; Epl, external plexiform layer; Ml, mitral cell layer; Grl, granule cell layer. Mitral cells are demarcated by arrows. Scale bars represent $100 \mu \mathrm{m}$ in panels A and B and $50 \mu \mathrm{m}$ in panels C and D. While losses in mitral cells in WT, ZrchI Prnp ${ }^{-/}$, Ngsk Prnp ${ }^{-1}$, Rikn Prnp ${ }^{-/}$and Rikn Prnp ${ }^{+/}$mice were small, a 30.5\% loss was observed in Rikn Prnp $^{-/}$mice (E). Differences of ${ }^{*} \mathrm{p}<0.01$ between WT and Rikn Prnp ${ }^{-/}$mice were considered significant with the unpaired Student's t-test. (F) Recognition and discrimination of odors using $>60$-week-old WT and Prnp ${ }^{-/}$mice. Odor recognition and discrimination tests were performed with $8 \mathrm{WT}, 5 \mathrm{ZrchI}$ Prnp ${ }^{-/}$and 16 Rikn Prnp ${ }^{-/}$mice. To assess the mobility of mice, the cage was divided in two equal halves with a demarcation line, and time-related body movements of the mouse from one half to the other half of the cage were measured. The cut-off time was designated as $300 \mathrm{sec}$. Columns representing the mean \pm standard errors of staying times on the side of the sterilized water (open) and the scented (2.5\% lemon extract) filter paper (closed) are illustrated accordingly. Differences of * $\mathrm{p}<0.01$ between two groups were considered significant, whereas differences of $\mathrm{p}>0.05$ were considered not significant (NS) with the paired Student's t-test. Bars show mean and standard errors.

Odor recognition was tested by excluding the influence of mobility (Fig. 2F). In this test, a cage was divided into two freely accessible equal halves by a demarcation line. The staying time of mice in one half of the cage was recorded with the use of a stopwatch when half of the body length (excluding the tail) of the animals had moved to the other half of the cage. Each mouse $>60$ weeks of age was observed for $5 \mathrm{~min}$. During the test, the WT, ZrchI Prnp ${ }^{-/}$and Rikn Prnp ${ }^{-/}$mice were placed on one half of the cage, and subjected to odorous stimuli with the scented filter paper for more than $150 \mathrm{sec}$. WT 
WT


ZrchI


Rikn

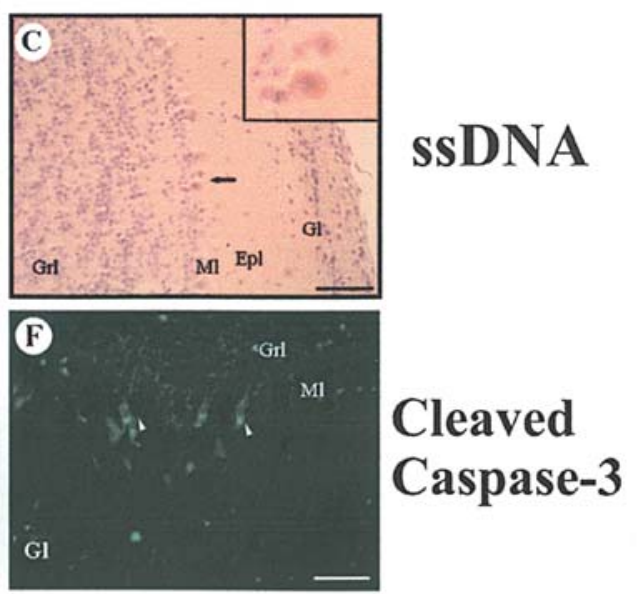

Figure 3. Apoptosis-specific immunohistochemical studies of the olfactory bulb of 80 -week-old WT and Prnp ${ }^{-/-}$mice. (A-C) Sections of the olfactory bulb in elderly WT and Prnp ${ }^{-/-}$mice were stained with an apoptosis-specific anti-ssDNA antibody. Although mitral cells of WT (A) and ZrchI Prnp ${ }^{-/-}$(B) mice were nonreactive, Rikn Prnp ${ }^{-/}$(C) mice displayed positive reactions. Each scale bar represents $100 \mu \mathrm{m}$ (A-C). (D-F) Apoptotic cells (arrow heads) in the mitral cell layer of 80-week-old Rikn Prnp ${ }^{-/}$(F) mice were detected by anti-cleaved caspase-3 antibody, whereas reaction values in age-matched WT (D) and ZrchI Prnp $^{-/}$(E) mice were below the detectable limits. Each scale bar represents $50 \mu \mathrm{m}$ (D-F). Gl, glomerular layer; Epl, external plexiform layer; Ml, mitral cell layer; Grl, granule cell layer.

and ZrchI Prnp ${ }^{-/}$mice immediately moved to the other half of the cage as the lemon extract was intensely stimulating to their olfactory sensations, whereas Rikn Prnp $^{-/}$mice stayed longer than WT and ZrchI Prnp ${ }^{-/-}$mice on the initial placement site despite exposure to the same stimulus. These results demonstrated that Rikn Prnp $^{-/}$mice showed a lower olfactory sensitivity than the other lines when subjected to the same odorous stimulus, implying that malfunctional effects of the olfactory bulb were probably induced during the process of aging.

To examine the glial fibrillary acidic protein (GFAP)specific expression levels in the main and accessory olfactory bulbs of Rikn $\mathrm{Prnp}^{-/}$mice, coronal sections were stained with the anti-GFAP antibody, and immunohistochemical findings of the brains were compared with age-matched WT mice. The main olfactory bulbs of Rikn Prnp $^{-/}$mice showed a higher number of astrocytes stained with GFAP antibodies (data not shown). At 20 weeks of age Rikn Prnp $^{-/}$mice indicated slight increases in astrocyte counts compared with WT and ZrchI Prnp ${ }^{-/}$mice (data not shown). Moreover, the accessory olfactory bulbs of Rikn Prnp $^{-/}$mice showed a similar tendency with slight increases in astrocyte counts in the granular cell layer at $>60$ weeks of age (data not shown).

The correlation of apoptosis with histologically altered mouse brains was investigated by immunohistochemical studies using various antibodies. In 80-week-old Rikn Prnp-/mice, mitral cells of the olfactory bulb were stained with the anti-single-stranded DNA (anti-ssDNA) antibody (Fig. 3AC). Expression of cleaved caspase- 3 and caspase-10 was monitored to determine the apoptotic process in mitral cells. Mitral cells undergoing apoptosis showed cleaved caspase-3 expression (Fig. 3D-F). Round apoptotic neurons appeared distorted with shrunken cytoplasm on staining. Notably, 20week-old Rikn Prnp ${ }^{-/}$mice demonstrated mitral cells with positive caspase-10 expression, albeit staining in 80-weekold Rikn Prnp ${ }^{-/-}$mice was not detectable (data not shown). In a similar negative tendency, staining of cleaved caspase-3 and caspase-10 antibodies in the young or elderly WT and ZrchI Prnp ${ }^{-1}$ mice was not detected in similar anatomical sites (data not shown).

The expression of Dpl mRNA was evaluated using reverse transcription-polymerase chain reaction (RT-PCR) with the brains and testes of WT, ZrchI and Rikn Prnp ${ }^{-/}$ mice. While three Prnp/Prnd chimeric mRNA bands were observed in the brains of Rikn Prnp ${ }^{-/}$mice, neither chimeric nor Prnd mRNAs (data not shown) were indicated in the tissue samples of ZrchI Prnp ${ }^{-/}$and WT mice (Fig. 4A). Chimeric mRNAs included RT-PCR products of 981, 818 and 717 bp. Prnd mRNA was indicated in the testes of WT, ZrchI Prnp ${ }^{-/-}$and Rikn Prnp ${ }^{-/}$mice. An RT-PCR product of 550 bp corresponding to Prnd mRNA was detected in all samples, and the sequence was completely identical (data not shown) to Ngsk Prnp ${ }^{-/}$mice (6). On reviewing expression of chimeric mRNAs in the brain, a similar non-discriminative expression pattern without site-specificity was portrayed in the cerebrum, cerebellum and olfactory bulb (Fig. 4A). RTPCR using RNA $(1 \mu \mathrm{g})$ from Rikn Prnp ${ }^{-/}$mice demonstrated that Prnp/Prnd chimeric mRNAs were detected in the olfactory bulb, cerebellum and cerebrum with strong signals of $818 \mathrm{bp}$, modest signals of $717 \mathrm{bp}$, and weak signals of $981 \mathrm{bp}$.

Western blot analysis using a polyclonal antibody against recombinant Dpl revealed a strong Dpl band in the brains of Rikn Prnp ${ }^{-/-}$mice, but not in those of ZrchI Prnp ${ }^{-/-}$and WT mice (Fig. 4B). Furthermore, PrP and Dpl were detected in the brains of Prnp ${ }^{+/}$mice. Studies on the distribution of Dpl in the cerebrum, cerebellum and olfactory bulb in 5- to 100week-old mice revealed that Dpl expression in these brain sites was age dependent (data not shown). The Dpl production level at 5 weeks of age was lower than that observed in the elderly mice (>60 weeks). In adult Rikn Prnp $^{-/-}$mice (>7-8 weeks), expression levels of Dpl among the cerebrum, cerebellum and olfactory bulb in each age group remained at 


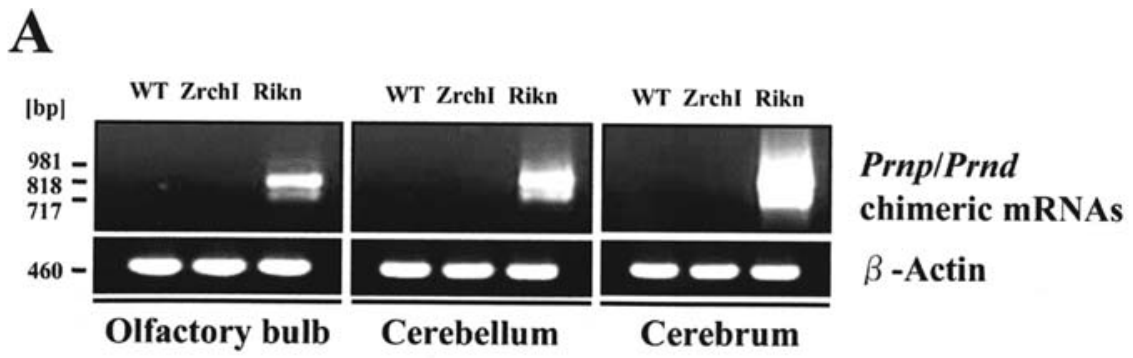

B

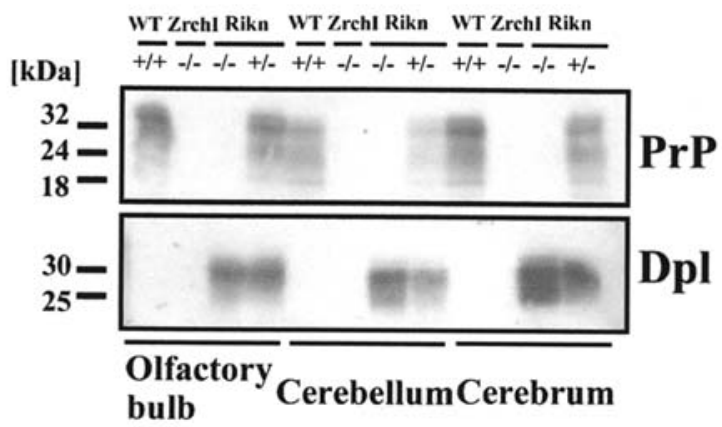

Figure 4. Detection of chimeric Prnp/Prnd mRNAs, PrP and Dpl in the brain. (A) RT-PCR for chimeric Prnp/Prnd mRNAs (981, 818 , 717 bp) in the olfactory bulb, cerebrum and cerebellum of 80 -week-old WT, ZrchI and Rikn Prnp ${ }^{-/-}$mice was performed with $B$-actin (460 bp) as an internal control. (B) Western blot analyses for PrP and Dpl in the cerebrum, cerebellum and olfactory bulb of 40-week-old WT, ZrchI Prnp ${ }^{-/}$, Rikn Prnp ${ }^{-/}$and Rikn Prnp ${ }^{+/}$ mice were conducted. Western blotting was performed with anti-PrP monoclonal antibody T2 and anti-Dpl rabbit antiserum. Each lane was loaded with $60 \mu \mathrm{g}$ of protein.

approximately the same level. Molecular weights of Dpl in the respective sites were approximately equal, viz. 25-30 kDa. The Dpl expression level was the lowest in adult cerebellum, and this may have resulted from Dpl-induced Purkinje cell death. In the olfactory bulb, intense Dpl expression was detected in Rikn Prnp ${ }^{-/}$and Prnp $^{+/-}$mice (Fig. 4B). Although PrP was detected in Rikn Prnp ${ }^{+/}$and WT mice (Fig. 4B), histopathological alterations were limited to Rikn Prnp ${ }^{-1-}$ mice. Dpl-induced abnormalities in the olfactory bulb were apparently suppressed by the induction of PrP in $\mathrm{Prnp}^{+/}$mice (data not shown).

\section{Discussion}

Rikn $\mathrm{Prnp}^{-/}$mice were generated by gene targeting. The entire Prnp with ORF and the 3' end of inform 2 were replaced with the pgk-neo gene (13). Homologous recombinant embryonic stem (ES) clones were injected into blastocysts of C57BL/6 mice to induce chimera production. Heterozygously mutated $\left(\mathrm{Prnp}^{+/-}\right)$mice with generated chimeras were first crossed with C57/BL6J mice, then intercrossed to eventually yield the Rikn Prnp ${ }^{-/}$mice $(8,9)$. The Rikn Prnp ${ }^{-/-}$ mice showed neural degeneration in the olfactory bulb, cerebellum, and brain stem at $>60$ weeks of age. Age-matched Rikn Prnp $^{+/+}$and Prnp $^{+/-}$littermate mice showed no neurodegeneration in the brain regions. Apparently, $\mathrm{PrP}^{\mathrm{C}}$ suppressed the olfactory degeneration in heterozygous or homozygous Prnp littermates. Differences in the targeting cassette $(8,9,13,14)$ might have caused higher abnormalities in Rikn Prnp $^{-/-}$mice.

In Rikn Prnp ${ }^{-/}$mice, pathological olfactory alterations were induced; histological alterations were not observed in the hippocampal area, albeit $\sim 30.5 \%$ of mitral cells were lost at 80 weeks of age. However, mitral cell loss was not induced in age-matched ZrchI Prnp ${ }^{-/-}$mice. Sakaguchi et al performed histopathological analyses of other brain regions in Ngsk mouse brains, though the olfactory bulb was not mentioned among the lesions they studied (5). So far, the olfactory bulb showed no pathological alterations in aged Ngsk mice, yet further examination is required in extremely aged $\mathrm{Ngsk}$ mice. It is still unclear whether olfactory degeneration and dysfunction are absent in aged ZrchII or Rcm0 mice. GFAPstaining showed a higher astrocyte count in the olfactory bulbs of Rikn Prnp ${ }^{-/}$mice than in other groups. Atarashi et al detected abundant Dpl mRNA in primary cultures of astrocytes derived from Ngsk Prnp ${ }^{-/}$mice (15). The ectopic $\mathrm{Dpl}$ on the surface of glial cells, in the absence of $\mathrm{PrP}^{\mathrm{C}}$, may have induced activation of astrocytes. Targeted expression of $\mathrm{PrP}^{\mathrm{C}}$ either in glial cells or on neurons in the cerebrum and cerebellum may be useful to elucidate the mechanisms of glial cell activation.

On Western blotting, the marked expression levels of Dpl among several brain regions (cerebrum, cerebellum and olfactory bulb) of Rikn Prnp $^{-/-}$mice showed a similar tendency except in the young (5 weeks old), viz. the Dpl level of the cerebellum was lower than the cerebrum in 5-week-old mice. Immunohistochemical investigations with various antibodies were conducted to correlate apoptosis with Dpl production in the mouse brain. At 80 weeks of age, Rikn Prnp ${ }^{-/}$mice exhibited an increased number of apoptosis-positive cells in the olfactory bulb, whereas none were found in age-matched WT and ZrchI Prnp ${ }^{-/-}$mice. Reactivities to cleaved caspase-3 and -10 antibodies were determined for a correlation with the apoptosis cascade in mitral cells of Prnp ${ }^{-/}$mice. The mitral cells 
undergoing apoptosis in Rikn Prnp ${ }^{-/-}$mice indicated cleaved caspase- 3 reactivity. Cleaved caspase-positive cells appeared morphologically different from non-apoptotic neurons. Although caspase-10 reactivity was observed in 20-week-old Rikn Prnp $^{-/}$mice, no reactivity was observed at 80 weeks of age. Differences in the sensitivity of immunohistochemistry using anti-cleaved caspase- 3 and -10 antibodies might have affected the results. In the case of the aged mice, all of the cells may have been prone to apoptosis, as they possibly had already been decimated by 80 weeks of age.

This study suggests that ectopically-expressed Dpl in the olfactory bulb of Rikn Prnp ${ }^{-/}$or $\mathrm{PrP}^{\mathrm{C}}$-deficient mice induced neuronal cell death that involved apoptosis and abnormal activation of glial cells. The interaction between Prnp and Prnd genes in mouse olfactory neurons might be physically correlated with the competition between $\mathrm{Dpl}$ and $\mathrm{PrPC}^{\mathrm{C}}$ in a common biochemical pathway where misregulation induced apoptosis. Although various hypothetical models have been proposed, the precise mechanism(s) of neurodegeneration in Rikn Prnp $^{-/}$mice remains to be elucidated.

The number of Purkinje cells was markedly decreased in aged Ngsk mice $(5,16)$. However, no pathological changes were detectable in the other investigated brain cells and cerebellar granule cells. Furthermore so far, we have detected no olfactory degeneration in aged Ngsk mice. These results suggest that neuron-expressed ectopic Dpl only caused degeneration of Purkinje cells in the absence of $\mathrm{PrP}^{\mathrm{C}}$ in $\mathrm{Ngsk}$ mice (16). Interestingly, neurodegeneration was observed only in Purkinje cells of the brains in Dpl-expressing ZrchI $\mathrm{Prnp}^{-/}$mice, where Dpl was expressed by other neurons as well (16). Although Moore et al reported that Purkinje, hippocampal pyramidal and granular cells were degenerated in Dpl-expressing tg-mice (17), our results demonstrated neurodegeneration or necrosis in not only the Purkinje cells but also the olfactory cells and brain stem neurons in Dplexpressing Rikn Prnp $^{-/}$mice.

There are three possible explanations for these findings: i) our gene-targeting approach afforded replacement of more nucleotides in intron 2 with the pgk-neo gene compared with Ngsk Prnp $^{-/-}$mice; ii) superoxide dismutase (SOD) activities in Rikn Prnp ${ }^{-/}$mouse brains were significantly $(\mathrm{p}<0.01)$ lower than those in WT mouse brains; and iii) Dpl expression levels were probably higher in the olfactory bulb and cerebellum of Rikn Prnp ${ }^{-/}$than those of ZrchII, Ngsk and Rcm0 Prnp $^{-/}$mice. Therefore, further studies to elucidate these possibilities are warranted. Note that in ii, differences in $\mathrm{Cu}$, Zn-SOD and Mn-SOD activities between WT, Ngsk and Prnp transgenic Ngsk mice were not significant (18). However, our previous report established that SOD activities are significantly lower in the brains of Rikn Prnp ${ }^{-/}$mice compared to WT mice (19). The results suggest that although Purkinje cells are the most vulnerable to Dpl toxicity, other brain neurons may not be spared Dpl-induced deleterious effects. This deleterious effect may be exacerbated by the suppression of SOD activity in Rikn Prnp ${ }^{-/}$mice (19). Therefore, it would be of interest to examine the involvement of the relevant molecules, such as reactive oxygen species, in the olfactory bulb and cerebellum in the course of neural degeneration.

The MHM2 (del 23-88 transgene), which encodes PrP lacking almost the entire octapeptide-repeat region, failed to prevent Purkinje cell death in aged Ngsk Prnp ${ }^{-/-}$mice (18). Through probably a similar mechanism, the $\operatorname{PrP} \Delta \# 1$ clone (deficient in the entire octapeptide-repeat region) failed to prevent apoptosis in the PrP-deficient cell line (19). The octapeptide repeat region has been demonstrated to be involved in copper binding (20), SOD-like activity of $\mathrm{PrP}^{\mathrm{C}}$ (21), and neuroprotection for Bax-induced apoptosis (22). The qualitative differences in the anti-apoptotic function of PrP-deletion mutants correlate well with the level of SOD activity in transfected cell lines expressing PrP-deletion mutants (23).

Dpl neurotoxicity executed in the absence of $\operatorname{PrP}$ is inhibited by PrP (24,25). Moreover, Dpl disturbs basolateral sorting of PrP in Madin-Darby canine kidney cells (26). As such, further studies are warranted to clarify whether the mechanisms of PrP-related Dpl neurotoxicity and Dpl inhibition are related to basolateral sortings of the two proteins in vivo.

\section{Acknowledgements}

We thank Dr Stanley B. Prusiner (Institute of Neurodegenerative Diseases, Department of Neurology and Department of Biochemistry and Biophysics, University of California) for providing Prnp $^{-/}$(ZrchI) mice, and the primary anti-Dpl rabbit antiserum from Dr Chen of Case Western Reserve University, Ohio, USA. The authors are grateful to Dr Anthony Foong for reading the manuscript. This study was supported by grant-in-aid (to K.S. and T.O.) from the Ministry of Health, Labour and Welfare of Japan, grant-inaid (to K.S.) for Scientific Research on Priority Areas and grant-in-aid (to K.S. and T.O.) for Scientific Research from the Ministry of Education, Science, Culture and Technology of Japan.

\section{References}

1. Oesch B, Westaway D, Walchli M, McKinley MP, Kent SB, Aebersold R, Barry RA, Tempst P, Teplow DB and Hood LE: A cellular gene encodes scrapie PrP 27-30 protein. Cell 40: 735-746, 1985.

2. Prusiner SB: Prions. Proc Natl Acad Sci USA 95: 13363-13383, 1998.

3. Bueler H, Fischer M, Lang Y, Bluethmann H, Lipp HP, DeArmond SJ, Prusiner SB, Aguet M and Weissmann C: Normal development and behaviour of mice lacking the neuronal cell-surface PrP protein. Nature 356: 577-582, 1992.

4. Manson JC, Clarke AR, Hooper ML, Aitchison L, McConnell I and Hope J: $129 /$ Ola mice carrying a null mutation in PrP that abolishes mRNA production are developmentally normal. Mol Neurobiol 8: 121-127, 1994.

5. Sakaguchi S, Katamine S, Nishida N, Moriuchi R, Shigematsu K, Sugimoto T, Nakatani A, Kataoka Y, Houtani T, Shirabe S, Okada H, Hasegawa S, Miyamoto T and Noda T: Loss of cerebellar Purkinje cells in aged mice homozygous for a disrupted PrP gene. Nature 380: 528-531, 1996.

6. Moore RC, Lee IY, Silverman GL, Harrison PM, Strome R, Heinrich C, Karunaratne A, Pasternak SH, Chishti MA, Liang Y, Mastrangelo P, Wang K, Smit AF, Katamine S, Carlson GA, Cohen FE, Prusiner SB, Melton DW, Tremblay P, Hood LE and Westaway D: Ataxia in prion protein (PrP)-deficient mice is associated with upregulation of the novel PrP-like protein doppel. J Mol Biol 292: 797-817, 1999.

7. Lee IY, Westaway D, Smit AF, Wang K, Seto J, Chen L, Acharya C, Ankener M, Baskin D, Cooper C, Yao H, Prusiner SB and Hood LE: Complete genomic sequence and analysis of the prion protein gene region from three mammalian species. Genome Res 8: 1022-1037, 1998. 
8. Kuwahara C, Takeuchi AM, Nishimura T, Haraguchi K, Kubosaki A, Matsumoto Y, Saeki K, Matsumoto Y, Yokoyama T, Itohara S and Onodera T: Prions prevent neuronal cell-line death. Nature 400: 225-226, 1999

9. Yokoyama T, Kimura KM, Ushiki Y, Yamada S, Morooka A, Nakashiba T, Sassa T and Itohara S: In vivo conversion of cellular prion protein to pathogenic isoforms, as monitored by conformation-specific antibodies. J Biol Chem 276: 11265-11271, 2001.

10. Kavaliers M, Colwell DD, Choleris E, Agmo A, Muglia LJ, Ogawa S and Pfaff DW: Impaired discrimination of and aversion to parasitized male odors by female oxytocin knockout mice. Genes Brain Behav 2: 220-230, 2003.

11. Sakudo A, Lee DC, Yoshimura E, Nagasaka S, Nitta K, Saeki K, Matsumoto Y, Lehmann S, Itohara S, Sakaguchi S and Onodera T: Prion protein suppresses perturbation of cellular copper homeostasis under oxidative conditions. Biochem Biophys Res Commun 313: 850-855, 2004.

12. Hayashi H, Takata M, Iwamaru Y, Ushiki Y, Kimura KM, Tagawa Y, Shinagawa M and Yokoyama T: Effect of tissue deterioration on postmortem BSE diagnosis by immunobiochemical detection of an abnormal isoform of prion protein. J Vet Med Sci 66: 515-520, 2004.

13. Sakudo A, Onodera T, Suganuma Y, Kobayashi T, Saeki K and Ikuta K: Recent advances in clarifying prion protein functions using knockout mice and derived cell lines. Mini Rev Med Chem 6: 589-601, 2006.

14. Sakaguchi S, Katamine S, Shigematsu K, Nakatani A, Moriuchi R, Nishida N, Kurokawa K, Nakaoke R, Sato H and Jishage K: Accumulation of proteinase $\mathrm{K}$-resistant prion protein (PrP) is restricted by the expression level of normal PrP in mice inoculated with a mouse-adapted strain of the Creutzfeldt-Jakob disease agent. J Virol 69: 7586-7592, 1995.

15. Atarashi R, Sakaguchi S, Shigematsu K, Arima K, Okimura N, Yamaguchi N, Li A, Kopacek J and Katamine S: Abnormal activation of glial cells in the brains of prion protein-deficient mice ectopically expressing prion protein-like protein, PrPLP/ Dpl. Mol Med 7: 803-809, 2001.

16. Yamaguchi N, Sakaguchi S, Shigematsu K, Okimura N and Katamine S: Doppel-induced Purkinje cell death is stoichiometrically abrogated by prion protein. Biochem Biophys Res Commun 319: 1247-1252, 2004.
17. Moore RC, Mastrangelo P, Bouzamondo E, Heinrich C, Legname G, Prusiner SB, Hood L, Westaway D, DeArmond SJ and Tremblay P: Doppel-induced cerebellar degeneration in transgenic mice. Proc Natl Acad Sci USA 98: 15288-15293, 2001 .

18. Atarashi R, Nishida N, Shigematsu K, Goto S, Kondo T, Sakaguchi S and Katamine S: Deletion of N-terminal residues 23-88 from prion protein ( $\mathrm{PrP}$ ) abrogates the potential to rescue PrP-deficient mice from PrP-like protein/doppel-induced neurodegeneration. J Biol Chem 278: 28944-28949, 2003.

19. Sakudo A, Lee DC, Saeki K, Nakamura Y, Inoue K, Matsumoto Y, Itohara $\mathrm{S}$ and Onodera $\mathrm{T}$ : Impairment of superoxide dismutase activation by $\mathrm{N}$-terminally truncated prion protein $(\mathrm{PrP})$ in PrPdeficient neuronal cell line. Biochem Biophys Res Commun 308: 660-667, 2003

20. Brown DR, Qin K, Herms JW, Madlung A, Manson J, Strome R, Fraser PE, Kruck T, von Bohlen A, Schulz-Schaeffer W, Giese A, Westaway D and Kretzschmar H: The cellular prion protein binds copper in vivo. Nature 390: 684-687, 1997.

21. Brown DR, Wong BS, Hafiz F, Clive C, Haswell SJ and Jones IM: Normal prion protein has an activity like that of superoxide dismutase. Biochem J 344: 1-5, 1999.

22. Bounhar Y, Zhang Y, Goodyer CG and LeBlanc A: Prion protein protects human neurons against Bax-mediated apoptosis J Biol Chem 276: 39145-39149, 2001.

23. Sakudo A, Lee DC, Nishimura T, Li S, Tsuji S, Nakamura T, Matsumoto Y, Saeki K, Itohara S, Ikuta K and Onodera T: Octapeptide repeat region and N-terminal half of hydrophobic region of prion protein $(\mathrm{PrP})$ mediate $\mathrm{PrP}$-dependent activation of superoxide dismutase. Biochem Biophys Res Commun 326: 600-606, 2005.

24. Nishida N, Tremblay P, Sugimoto T, Shigematsu K, Shirabe $S$, Petromilli C, Erpel SP, Nakaoke R, Atarashi R, Houtani T, Torchia M, Sakaguchi S, DeArmond SJ, Prusiner SB and Katamine S: A mouse prion protein transgene rescues mice deficient for the prion protein gene from purkinje cell degeneration and demyelination. Lab Invest 79: 689-697, 1999.

25. Sakudo A, Lee DC, Nakamura I, Taniuchi Y, Saeki K, Matsumoto Y, Itohara S, Ikuta K and Onodera T: Cell-autonomous PrP-Doppel interaction regulates apoptosis in PrP genedeficient neuronal cells. Biochem Biophys Res Commun 333: 448-454, 2005.

26. Uelhoff A, Tatzelt J, Aguzzi A, Winklhofer KF and Haass C: A pathogenic PrP mutation and doppel interfere with polarized sorting of the prion protein. J Biol Chem 280: 5137-5140, 2005. 